Research Article

\title{
Impact of Attitudinal Ambivalence on Safety Behaviour in Construction
}

\author{
Sheng Xu $\mathbb{D}^{1,2}$ Patrick X. W. Zou, ${ }^{3}$ and Hanbin Luo ${ }^{4}$ \\ ${ }^{1}$ School of Economics and Management, Chang'An University, Middle Section, South 2nd Ring, Xi'an 710064, China \\ ${ }^{2}$ Research Center of Digital Engineering for Traffic Infrastructure Construction and Management in Shaanxi Province, \\ Xi'an 710000, China \\ ${ }^{3}$ Department of Civil and Constriction Engineering, Centre for Sustainable Infrastructure, Swinburne University of Technology, \\ Hawthorn, VIC 3122, Australia \\ ${ }^{4}$ School of Civil Engineering and Mechanics, Huazhong University of Science and Technology, 1037 Luoyu Road, \\ Wuhan 430074, China \\ Correspondence should be addressed to Sheng Xu; sheng.xu@chd.edu.cn
}

Received 17 April 2018; Accepted 7 June 2018; Published 26 July 2018

Academic Editor: Yingbin Feng

Copyright (c) 2018 Sheng Xu et al. This is an open access article distributed under the Creative Commons Attribution License, which permits unrestricted use, distribution, and reproduction in any medium, provided the original work is properly cited.

\begin{abstract}
Unsafe acts have been identified as a major factor of construction accidents. The Theory of Planned Behaviour (TPB) has been used to explain the factors influencing unsafe behaviour, by establishing the relationship between attitude, intention, and behaviour. However, the existing research on the relationship between safety attitude and safety behaviour could not fully explain the decisionmaking process of unsafe acts, in that the relationship could be mediated by attitudinal ambivalence, which is caused by conflicting information sources and the social network pressure of peer workers. This research examined whether attitudinal ambivalence was a mediating factor, either fully or partially, in the relationship between safety attitude and safety behaviour by expanding the TPB model. Data were collected from questionnaire survey of 228 construction workers. The results showed that attitudinal ambivalence existed as a partial mediating factor in the relationship between safety attitude and safety behaviour. This paper contributed to the body of knowledge on safety management by recognizing the role of attitudinal ambivalence in construction workers and integrated it into the TPB model. This research will be helpful in providing greater understanding of the dynamic and complex decision-making process of unsafe behaviour given multiple information sources and conflicting environments.
\end{abstract}

\section{Introduction}

Construction is one of the most important industries worldwide as it provides up to $10 \%$ employment and economic growth. However, construction has also been classified as one of the most hazardous industries across the world [1-3]. Safety accidents cause fatalities, injuries, financial losses, and schedule overruns, and it may even impact construction workers' family life and welfare due to the spillover effect of the safety climate at work [4]. It is well accepted that a decrease in the number of workers' unsafe acts can improve the safety performance of construction projects, and substantial research efforts have been undertaken aiming to eliminate unsafe acts. One stream of efforts addresses workers "not knowing" work-associated risks and aims to improve safety training [5] and teach them what to do to accomplish their job safety. Another stream of research addresses workers "not willing to perform safely" [6], which could be caused by a series of factors at the individual, group, and organizational levels [7]. Individually, "not willing to perform safely" can be considered as a decision-making process [8] and can be explained with psychological theories because they address how the mind, perceptions, and beliefs influence safety behaviour. The prevailing theoretical framework of unsafe acts is the Theory of Planned Behaviour (TPB) [9], and it has been widely applied to analyse unsafe acts in construction $[10,11]$ and other research fields.

However, a series of theoretical and empirical studies [12] showed that various factors at the organizational and individual levels play important roles in the decision-making process and those factors can be conflicting. The Theory of Planned Behaviour does not harbour the attitudinal 
ambivalence that is caused by conflicting factors leading to unsafe acts and therefore provides an incomplete picture of the possible relationship between safety attitude and safety behaviour. The research into contradictory factors with positive and negative effects and their influence on safety behaviour is still in its infancy.

The ambivalence comes from the conflicts in cognitive and affective attitudes. In construction safety, conflicts may happen in several ways. First, the priority of safety could be conflicting with an emphasis on schedule or cost. Second, construction workers may change their safety acts when they choose to enjoy the convenience or are under stress, anger, and difficult operating conditions [13]. Third, safety trainings can be conflicting with habitual unsafe behaviour in construction groups, which may lead to unsafe behavioural intent when the habitual unsafe behaviour prevails. Fourth, safety attitudes and safety behaviour can be inconsistent among different team members, and the influence from their coworkers can be greater than that from the project organization's higher safety management, which makes it harder for safety leadership to be effective in construction crews.

The abovementioned bipolar continuum of safety attitude could be described with attitudinal ambivalence. Attitudinal ambivalence was identified in social psychology in the 1990s, and it was referred to the coexistence of positive and negative cognitive appraisal and affective experience towards certain objects [14]. Recently, it has been used in the research of safety attitude and unsafe behaviour [15]. Under multiple information sources and a variety of psychological effects, unsafe acts of construction workers can be propagated, accumulated, and repetitive [16].

In this research, we examined the ambivalence of their attitude towards unsafe acts that may be influenced by their cognitions of safety risks, their communications with their peer workers and foremen, and the organizational priorities over safety. The conflicting information sources and the social network pressure of peer workers caused ambivalent attitude over safety acts and influenced the relationship between their safety attitude and behaviour. Establishing the effect of attitudinal ambivalence on unsafe behaviour will be helpful to understand the dynamic and complex decision-making process of unsafe behaviour.

In the next sections, the concept of attitudinal ambivalence and the identified group influence on construction workers' unsafe acts will be discussed, and the possible role of attitudinal ambivalence will be hypothesized for model fitting and comparison. Then, the questionnaire of construction workers' usage of personal protective equipment will be introduced. The results will be examined, and the model will be fitted to decide whether attitudinal ambivalence is one of the factors leading to unsafe acts. In the end, a discussion and concluding remarks will be provided to help construction managers control unsafe behaviour by the control of attitudinal ambivalence.

\section{Theoretical Background and Research Hypothesis}

2.1. TPB and Construction Safety Research. Ajzen developed the Theory of Planned Behaviour (TPB) and identified factors of human behaviour, which included attitude, subjective norm, and perceived behavioural control [17]. Attitude refers to the value attributed to the performance of the behaviour, and the most favourable behaviour is more likely to happen. The subjective norm indicates social pressure to perform certain behaviour; the behaviour under greater pressure is more likely to happen. The perceived behavioural control refers to a prejudgement of the possibility of performing certain behaviours; the easier behaviour is more likely to happen. The intention is an indication of a person's readiness to perform a given behaviour, and it is considered to be the immediate antecedent of behaviour. The TPB considers individual and environmental influence and could be used to explain human behaviour in a satisfactory extend. A search of existing literature showed that TPB has been cited more than 10,000 times and successfully applied in various research fields to predict safety-related behaviour such as unsafe driving behaviour [18], green exercise [19], and the relationship between safety climate and unsafe behaviour [10, 11].

To promote safe behaviour on construction sites, previous researchers measured safety attitude [24], analysed the relationship between safety attitude and safety performance [25], and discussed how safety interventions could improve safety attitude and performance [26]. Mohamed et al. found that workers' attitudes towards safety responsibilities and their risk perceptions explained their intentional behaviour [27]. Some of the research had identified that safety attitude could be under conflicting influencing factors and it is possible to impact the relationship between attitude and behaviour. In this research, by applying theoretical model fitting, the causal effect of attitude on behaviour can be further explored and discussed.

In construction safety, Cavazza and Serpe used TPB to argue that the improvement of safety performance was caused by psychological changes and positive attitudes after safety training programmes [15]. Fang developed a framework of social psychological causes of unsafe behaviour based on the TPB and used it to discuss the relationship between safety attitude and unsafe behaviour [8]. Goh and Binte Sa'adon used TPB to identify the key variable of the cognitive decisionmaking process of unsafe behaviour of scaffolders [20].

Applications of TPB model often expanded it with extra factors to better explain unsafe behaviour, as TPB was an open theoretical framework and new factors could be added to improve the explanation of human behaviour. The descriptive norms were distinguished from injunctive norms to better predict intentions and behaviour [21]. Other factors were added to TPB model as the leading factors of attitude and subjective norms, which included past behaviour and habits, belief salience, morality, and self-identity [22], and moral norms, which included self-identity and group identity [23]. In this research, a focus was placed on the attitude factor; particularly, this research expanded the construct of attitude and introduced the concept of ambivalent attitude.

2.2. Attitudinal Ambivalence. Various factors may lead to conflicting information and stimuli regarding construction workers' safety attitude [28], and those factors may come from the individual level, the group level, and the 
organizational level. For example, Wu et al. identified management safety commitment, team safety climate, and personal safety responsibility as factors of safety attitudes [29]. Safety training not only increases safety knowledge but also improves safety climate on site and could be a positive factor of construction workers' safety attitude. On the other hand, acting in a safe way may sacrifice comfort and convenience. For example, dumper drivers may not get off the truck every time during unloading because they tried to save some efforts [30]; workers may also refuse to wear helmets because it is too hot in the summer. These conflicting factors may lead to the unstable, incongruent, and ambivalent safety attitude in construction crews. In addition, attitudes towards safety in the construction industry were affected by past experience; victims of accidents tended to be more careful while nonvictims felt confident about their own behaviour [31].

Construction crew members are under great peer pressure from their groups to behave unsafely if unsafe behaviour prevails, and construction managers' commitment to safety could be conflicting with the unsafe behaviour of the construction coworkers. Zohar and Tenne-Gazit stated that interaction and leadership were the predictive factors of the emergence of organizational climate [32], and safety culture emerged from the interactions and influence of multiple organizations [33]. In small and medium construction groups, frank and frequent safety communication between construction workers and managers could improve safety performance [34]. Friendship network in the construction crews can compensate poor safety climate [35], and social pressure in crews can influence the strength of safety climate [11]. Novice and younger construction workers relied on the communications with their peers to attain safety knowledge [36]. The safety performance of migrant or ethnic minority workers being worse than that of local workers could also result in the negative safety attitudes as a group [37].

Therefore, it is necessary to study the existence and measurement of contradictory attitude towards safety behaviour, and attitudinal ambivalence may provide an explanation of the cognitive decision-making process with individual's intent of unsafe acts. Attitudinal ambivalence describes the coexistence of positive and negative attitude elements. Ambivalent attitude comes from conflicts among cognitive and affective dimensions of attitude, either within these dimensions or between them [38]. Intracomponent ambivalence stands for the coexistence of positive and negative cognitions or feelings against certain attitude objects. For example, believing PPE an effective protection from danger but useless in safe environment is ambivalence within the cognitive attitude, while feeling protected by personal protective equipment and feeling tedious wearing them are ambivalence within the affective attitude. Intercomponent ambivalence stands for the coexistence of positive cognition and negative feelings or that of negative cognitions and positive feelings towards attitude objects. For example, knowing to wear safety helmets and feeling uncomfortable wearing them represent ambivalence between cognitive and affective attitudes.

The measurement of attitudinal ambivalence could be direct or indirect. Respondents could be asked directly if they have conflicting beliefs and feelings towards unsafe acts
[39], or they could be asked to rate the extent of their positive and negative beliefs and feelings separately, and the response would be calculated to indicate ambivalence [40].

Psychological studies have verified that conflicts could weaken behavioural intentions or the relationship between attitudes and behaviour [41]. Cavazza and Serpe found that attitudinal ambivalence can mediate the impact of safety climate on complying with the safety behaviour rules [15]. However, safety climate is a collective phenomenon, and individually, safety behaviour is influenced by safety attitude. This research concerns the cognitive decision-making process of safety behaviour by studying the ambivalent safety attitude. As such, the aim of this research was to examine how the ambivalent attitude takes effect in the relationships between safety attitude and safety behaviour by using TPB.

2.3. Research Hypothesis. According to the Theory of Planned Behaviour [9], safety attitude, subjective norms, and perceived behavioural control all have a positive correlation with safety intent, which is closely related to safety behaviour. Therefore, this research established Hypothesis 1 as follows: safety attitude, subjective norms, and perceived behavioural control have a positive correlation with safety intent.

Given the above discussion, attitudinal ambivalence has an impact on the relationship between safety attitude and safety behaviour. However, the path of the impact was still unclear. Existing literature argued that attitudinal ambivalence made behavioural decisions harder to make [42], as well as decreased the consistency of attitude and the confidence of certain behaviour [43] because the ambivalence undermined the persistence, resistance, and information process of attitude.

In line with the abovementioned literature on attitudinal ambivalence, this research proposed the hypothesis that attitudinal ambivalence had a mediating impact, at least in part, on the relationship of safety attitude and safety intention. The fully mediating impact means that the direct path from the independent variable to the indicator is zero, while the partially mediating impact means that the direct path from the independent variable to the indicator is decreased by the mediator. Therefore, this research compared the fully and partial mediating models to examine the impact path of attitudinal ambivalence, as shown in Figure 1. The fully mediating model suggests that safety attitude does not directly influence safety behaviour intent without the impact of attitudinal ambivalence, while the partial mediating model suggests that attitudinal ambivalence weakens the impact of safety attitude on safety behaviour intention. Attitude influenced behavioural intention immediately, and behaviour is highly related to intention. On the other hand, behaviour with objective but questionnaire could be subjective and not a best way to gather behaviour data. Therefore, this research did not include behaviour data in the model and the questionnaire. Correspondingly, the hypothesis is as follows:

H1: Safety attitude, subjective norms, and perceived behavioural control have a positive correlation with safety intent. 


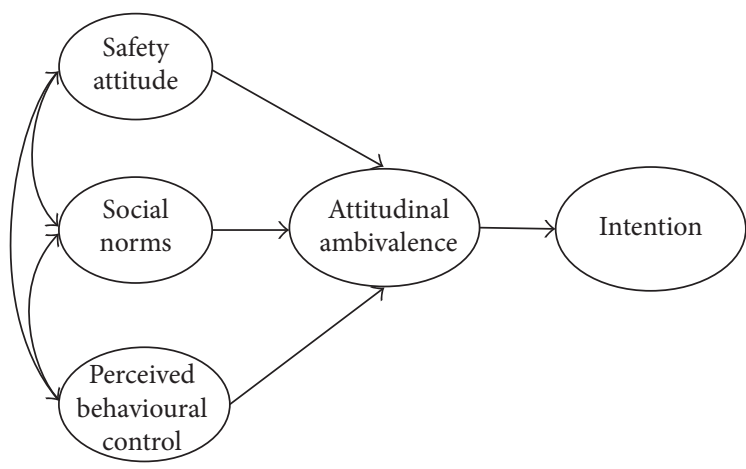

(a)

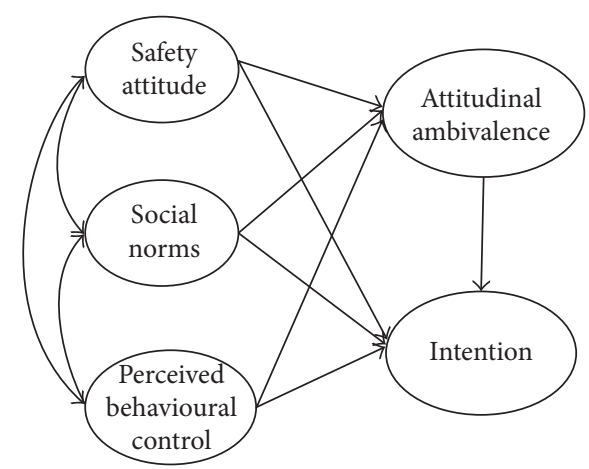

(b)

FIgURe 1: Fully mediating model (a) and partial mediating model (b).

H2a: Attitudinal ambivalence fully mediates the correlation of safety attitude, subjective norms, and perceived behavioural control with safety intent.

H2b: Attitudinal ambivalence partially mediates the correlation of safety attitude, subjective norms, and perceived behavioural control with safety intent.

\section{Survey Questionnaire Development}

The failure to correctly wear personal protective equipment (PPE) was chosen as the behaviour of discussion instead of general "unsafe acts" because PPE could help workers avoid injuries when falling from heights and struck by objects, which combined could account for more than $70 \%$ of all accidents in construction in the US and more than $60 \%$ in China. Thus, the use of PPE was an essential act of safety that could greatly reduce the number of injuries.

3.1. Measurement of Safety Attitude. Existing literature has developed statements to measure safety attitudes; these statements were adapted to PPE usage. The measurement of safety attitude contained items to assess cognitive and affective attitudes towards safety behaviour and risk perceptions [44]; safety values and internal tendencies [45]; with the focus on the workers' perception of PPE and their risk assessment. In this research, the statements were adapted from Braham [46] including whether workers were aware of the circumstances for using PPE, the benefits of using it, and the risks of not using it. Nine statements were developed for safety attitudes.

3.2. Measurement of Attitudinal Ambivalence. For the attitudinal ambivalence component, questions included direct emotions towards PPE, satisfaction with PPE usage, and past experience. The way we adapted to develop the attitudinal ambivalence statements was to select positive and negative statements of feelings towards safety behaviour from various sources $[39,46]$ and to gather seven descriptive words to describe the feelings, as well as another two questions about their past experience gaining benefits from using PPE and their overall satisfaction of the PPE management on site.
3.3. Subjective Norms and Perceived Behavioural Control. The measurement for subjective norms, perceived behavioural control, intention, and behaviour was also developed. Subjective norms were the perceived beliefs regarding the social norms of group behaviour; thus, the statements represented "what other people would do" and "what other people might think." The influence of interpersonal relationship on their behaviour was also measured through statements including "good relationships with my coworkers help me wear PPE correctly" [47]. The subjective norms usually came from supervisors, coworkers, and family, so four statements were developed for subjective norms. For perceived behavioural control, six statements were used to measure how much control they believe they have on using PPE based on Ajzen [9] to discover the perceived behavioural control under normal and abnormal situations, as well as conditions perceived as necessary. The intention was measured with the frequency of using PPE in the future.

3.4. Choosing Appropriate Items for the Instrument. A total of 50 statements were developed in the survey questionnaire, and they were revised by an expert focus group consisting of five engineers, who were in charge of project safety and quality and had more than five years of experience, and five academics in construction safety. The focus group session first checked for double-barrelled questions, and six statements were identified as redundant and deleted. Second, every statement was worded to be plain, simple, clear, and direct in language to ensure clarity and ease of comprehension. Third, the focus group reviewed the questionnaire, and participants in the group provided their experience with the PPE issue on site, deleted another four statements that did not represent the workers' experience and concerned on using PPE, and rephrased five statements to better describe their experience.

Overall, 31 statements were ultimately chosen for the questionnaire, which were also called "items" in this research. They consisted of eight items for safety attitude, items SA1 to SA8; eight items for attitudinal ambivalence, items AA1 to AA8; five items for subjective norms, items SN1 to SN5; seven items for perceived behavioural control, item PBC1 to PBC7; and 3 items for intentions, items INT1 to INT3. All questions asked workers to express the 
level of agreement (or disagreement) on a five-point Likerttype scale, but answers for each question varied according to their particular statement. In addition, the questionnaire also included five demographic questions about respondents' age, gender, trade, education and training, and number of years working in the construction industry.

\section{Data Collection and Analysis}

4.1. Data Collection. The survey questionnaire in Chinese was distributed to 290 workers in ten construction sites in Dongguan, Guangdong Province, and Wuhan, Hubei Province, in China, including five commercial construction sites and five metro construction sites. The commercial construction sites were chosen randomly from all government-invested projects in Dongguan, and the metro sites were also chosen randomly from all metro construction sites in Wuhan. The project managers and site foremen helped with the onsite distributions of the anonymous survey questionnaire, but they were not aware of the content of the questionnaire. All instructions were given by the researchers directly to the workers, so that the responses were trustworthy and under no manipulation. Workers were asked to gather in a large room on site after lunch, so that completion of the questionnaire would not interrupt their work. The researchers explained that the survey was purely for scientific research and the confidentiality would be guaranteed and that the data from the questionnaire were anonymous and collected directly by the researchers. The questionnaire survey took 20 minutes at each site.

In total, 278 sets of questionnaires were collected. Data preprocessing showed that 27 respondents did not answer all the questions. Another 23 respondents had answers that were identical to those of others and therefore might not be willing to answer the questionnaire seriously and copied their coworkers' responses. Their responses were no longer suitable for further analysis. As a result, data preprocessing excluded 27 incomplete sets of data and 23 sets of duplicate data. As a result, 228 sets of data ( $78.6 \%$ responses rate) were valid and analysed with SPSS.

4.2. Data Analysis. In the 228 valid responses, 198 of the respondents were male and 30 were female. They covered a variety of trades, including bar benders, concrete workers, scaffolding workers, electricians, labourers, carpenters, masons, and drivers. Only five respondents had received high school education, and $72 \%$ of the respondents were 20 to 39 years old. A total of $37.5 \%$ of them had worked in the construction industry for less than three years, and approximately $10 \%$ of them had worked in the industry for more than eight years.

The intraconstruct reliabilities were examined with Cronbach's alpha as shown in Table 1. Cronbach's alpha must be larger than 0.7 to indicate good reliability. Cronbach's alpha values for all constructs were above 0.7 , suggesting strong internal consistency of all measures. Therefore, the reliability of the questionnaire was verified. Table 2 also shows the result of the corrected item-total
Table 1: Confirmatory factor analysis.

\begin{tabular}{|c|c|c|c|c|}
\hline Items & & Factors & $\begin{array}{l}\text { Standard } \\
\text { estimates }\end{array}$ & $p$ \\
\hline SA7 & $<---$ & \multirow{7}{*}{ Safety attitude factor } & 0.622 & - \\
\hline SA6 & $<---$ & & 0.802 & $* * *$ \\
\hline SA5 & $<---$ & & 0.829 & $* * *$ \\
\hline SA4 & $<---$ & & 0.868 & *** \\
\hline SA3 & $<---$ & & 0.843 & $* * *$ \\
\hline SA2 & $<---$ & & 0.868 & $* * *$ \\
\hline SA1 & $<---$ & & 0.856 & *** \\
\hline AA 8 & $<---$ & \multirow{6}{*}{ Attitudinal ambivalence factor } & 0.666 & $* * *$ \\
\hline AA5 & $<---$ & & 0.836 & $* * *$ \\
\hline AA4 & $<---$ & & 0.844 & $* * *$ \\
\hline AA3 & $<---$ & & 0.880 & $* * *$ \\
\hline AA2 & $<---$ & & 0.771 & $* * *$ \\
\hline AA1 & $<---$ & & 0.749 & $* * *$ \\
\hline PBC6 & $<---$ & \multirow{6}{*}{ Perceived behavioural control factor } & 0.716 & $* * *$ \\
\hline $\mathrm{PBC} 5$ & $<---$ & & 0.715 & $* * *$ \\
\hline PBC3 & $<---$ & & 0.855 & $* * *$ \\
\hline $\mathrm{PBC} 2$ & $<---$ & & 0.812 & $* * *$ \\
\hline PBC1 & $<---$ & & 0.664 & $* * *$ \\
\hline $\mathrm{PBC7}$ & $<--$ & & 0.582 & $* * *$ \\
\hline SN1 & $<---$ & \multirow{5}{*}{ Subjective norm factor } & 0.914 & $* * *$ \\
\hline SN2 & $<---$ & & 0.949 & $* * *$ \\
\hline SN3 & $<---$ & & 0.874 & $* * *$ \\
\hline SN4 & $<---$ & & 0.796 & $* * *$ \\
\hline SN5 & $<---$ & & 0.834 & *** \\
\hline
\end{tabular}

Note. ${ }^{* * *}$ Significance level is $p<0.001,{ }^{* *}$ significance level is $p<0.01$, and * significance level is $p<0.05$.

TABLE 2: Correlation and credibility test.

\begin{tabular}{lcc}
\hline Factors & Items & Correlation \\
\hline & SA1 & 0.822 \\
& SA2 & 0.835 \\
Safety attitude factor & SA3 & 0.822 \\
Cronbach's alpha $=0.945$ & SA4 & 0.837 \\
& SA5 & 0.805 \\
& SA6 & 0.779 \\
& SA7 & 0.811 \\
& SA8 & 0.354 \\
\hline & AA1 & 0.604 \\
Attitudinal ambivalence factor & AA2 & 0.702 \\
Cronbach's alpha $=0.816$ & AA3 & 0.814 \\
& AA4 & 0.751 \\
& AA5 & 0.776 \\
Subjective norm factor & AA6 & 0.449 \\
Cronbach's alpha $=0.797$ & AA7 & -0.293 \\
Cronbach's alpha $=0.742$ & AA8 & 0.677 \\
\hline & PBC1 & 0.538 \\
& PBC2 & 0.714 \\
& PBC3 & 0.698 \\
& PBC4 & -0.081 \\
& PBC5 & 0.646 \\
& PBC6 & 0.607 \\
& PBC7 & 0.568 \\
\hline & SN1 & 0.556 \\
& SN2 & 0.791 \\
SN3 & 0.766 \\
& SN4 & 0.583 \\
& SN5 & 0.568 \\
\hline & & \\
& &
\end{tabular}


correlation analysis, which was to make sure that every item was correlated with other statements within the same construct. The value should be larger than 0.5 to suggest a good correlation within constructs. Items SA8, AA6, AA7, and PBC4 were deleted for their low interconstruct correlation scores, which suggested poor correlation with other statements and those statements was not measuring the same construct [48]. When deleted, Cronbach's alpha value would be above 0.5 , and the reliability would be significantly increased. Close examination of these deleted statements revealed that SA8 could be too vague for respondents to answer and should be excluded from the safety attitude factor; AA6 was about a general feeling of working safety, and AA7 was about an attitude to learn the use of PPE, and these two should not have been used to measure attitudinal ambivalence; and PBC4 was more likely an evaluation of behavioural intent.

Next, confirmatory factor analysis was conducted with AMOS 18.0. Each construct was examined to check whether the measurement was unidimensional. Fitness was assessed by chi-square and $\chi^{2} / d f$ value, Comparative Fit Index (CFI), Tucker-Lewis Index (TLI), and root mean square error of approximation (RMSEA). Good fit of model should follow the criteria of $\chi^{2} / d f$ less than 3 , CFI and TLI greater than 0.90 , and RMSEA less than 0.08. Confirmatory factor analysis also indicated the convergent validity. The standardized factor loading should be at least 0.5 and ideally 0.7 . The analysis showed that the factor loading for most statements was above 0.7 , except SA7 was not significantly related to safety attitude, which was unacceptable. In order to obtain good model fit and achieve validity, SA7 was deleted. Furthermore, the factor loading for AA8 and PBC7 was 0.582 and 0.666 , and they were also excluded for the model fitting. The final results are shown in Table 1 and note that symbol "<---" means the items in the first column are the constituents of the constructs in the second column.

\section{Results and Discussion}

5.1. Results. Structural equation modelling (SEM) was used to fit the TPB model and reveal the correlation among components. SEM can be considered as a series of tools for data analysis to test theoretically derived and priori specified causal hypotheses (Mueller and Hancock, 2008). In SEM, variables are distinguished as latent variables and measured variables. The traditional and typical SEM applications can be divided into the following three categories: a measured variable path analysis, which explores the hypothesized causal relations among measured variables; a confirmatory factor analysis, which explores the causal relations between latent variables and measured variables; and the latent variable path analysis, which explores the causal relations among latent constructs.

At first, the fully mediating TPB framework in Figure 1 was fitted, as shown in Table 3, where the column "standard estimates" indicates the estimated regression weight, the column "standard error" indicates the standard error of regression weights, the column "critical ratio" indicates the critical ratio as dividing the regression weight estimate by the estimate of its standard error and corresponds to the last column indicating p-value. A $p$ value of 0.05 , which is considered significant, requires a critical ratio of 2.07 . The criteria used in confirmatory factor analysis were also applied here to determine whether the model was a good fit. The results show that the fully mediating model was not a good fit, since CFI was 0.894 , and it had to be more than 0.9 to be a good fit. The RMSEA was 0.094, and it had to be less than 0.08 to be a good fit. Note that the symbol "<---" means that the constructs on the right of the sign were factors influencing the constructs on the left.

Then, the partial mediating model was examined, and it turned out to be a good fit $\left(\chi^{2} / d f=2.338, \mathrm{CFI}=0.934\right.$, TLI $=0.913$, RMSEA $=0.077)$, as shown in Table 4 and Figure 2. In Figure 2, rectangles represent observed variables or questionnaire statements; small circles on the left side represent the residue; big circles represent latent factors, including model constructs; and arrows represent path directions and coefficient estimates, and the path significance is shown on each arrow. The single directional arrows denote the definite relationship between the related constructs, while the double directional arrows denote the covariances among constructs and those relationships were not included in the model or the hypothesis, and thus, no significance value was shown on these bidirectional arrows. A path was considered significant if the significant level of the path was under 0.05 . In this model, the predictors of behaviour explained $82.0 \%$ of its variance, and the predictors of intention explained $88.1 \%$ of its variance. Note that the symbol "<---" means the constructs on the right of the sign were factors influencing the constructs on the left.

Overall, the parameter fits and estimates supported $\mathrm{H} 1$ and $\mathrm{H} 2 \mathrm{~b}$, the partial mediating role of attitudinal ambivalence in the relationship between safety attitude and behavioural intention in Section 2.3. The expanded TPB model was suitable for modelling the partial mediating role of attitudinal ambivalence in the safety attitude and safety intention relationship. The moderate model confirmed factors of intentions and suggested that ambivalent attitude was an important factor of unsafe behaviour intention.

5.2. Discussion. This research investigated the influencing factors and paths of construction workers' intentions to behave unsafely. The questionnaire survey results supported the expanded TPB model with attitudinal ambivalence as a partial mediating factor of unsafe intentions. The results also corresponded with those of psychological research on health risk-related behaviour, including the finding that changes in attitudes were caused by strengthened recognition of target behaviour and that social norms and perceived behavioural control both have substantial influence on intentions.

The results suggested that the change in unsafe behaviour intentions was greatly impacted by ambivalent attitude and perceived behavioural control. However, the link between safety attitude and behaviour intentions was weak. One of the explanations could be that because the ambivalent attitude was considered in the model, it took place of the safety attitude. When construction workers had an ambivalent attitude towards safety acts during their decision-making process, they hesitated and may not have taken actions following their cognition and perception on 
TABLE 3: Fitting results of fully mediating model.

\begin{tabular}{|c|c|c|c|c|c|c|}
\hline & & & Standard estimates & Standard error & Critical ratio & $p$ \\
\hline Intention & $<---$ & Attitudinal ambivalence & 0.709 & 0.149 & 4.756 & $* *$ \\
\hline Attitudinal ambivalence & $<---$ & Perceived behavioural control & 0.997 & 0.099 & 10.401 & *** \\
\hline Attitudinal ambivalence & $<---$ & Safety attitude & 0.065 & 0.057 & 1.015 & 0.310 \\
\hline Attitudinal ambivalence & $<---$ & Subjective norms & 0.009 & 0.034 & 0.192 & 0.848 \\
\hline
\end{tabular}

$\chi^{2}(203)=608.214, \chi^{2} / d f=2.996$, CFI $=0.894$, RMSEA $=0.094$. Note. ${ }^{* * *}$ Significance level is $p<0.001,{ }^{* *}$ significance level is $p<0.01$, and ${ }^{*}$ significance level is $p<0.05$.

TABLE 4: Fitting results of partial mediating model.

\begin{tabular}{|c|c|c|c|c|c|c|}
\hline & & & Standard estimates & Standard error & Critical ratio & $p$ \\
\hline Intention & $<---$ & Attitudinal ambivalence & 0.813 & 0.230 & 4.116 & $* * *$ \\
\hline Attitudinal ambivalence & $<---$ & Perceived behavioural control & 0.261 & 0.367 & 0.955 & 0.340 \\
\hline Attitudinal ambivalence & $<---$ & Safety attitude & 0.850 & 0.459 & 2.910 & $*$ \\
\hline Attitudinal ambivalence & $<---$ & Subjective norms & 0.155 & 0.060 & 3.224 & $* *$ \\
\hline Intention & $<---$ & Perceived behavioural control & 0.730 & 0.291 & 3.483 & $* * *$ \\
\hline Intention & $<---$ & Subjective norms & 0.453 & 0.137 & 3.316 & $* * *$ \\
\hline Intention & $<---$ & Safety attitude & 0.090 & 0.107 & 1.087 & $*$ \\
\hline
\end{tabular}

$\chi^{2}(234)=546.996, \chi^{2} / d f=2.338, \mathrm{CFI}=0.934, \mathrm{RMSEA}=0.077$. Note. ${ }^{* * *}$ Significance level is $p<0.001,{ }^{* *}$ significance level is $p<0.01$, and ${ }^{*}$ significance level is $p<0.05$.

the safety acts. Therefore, the direct effect of safety attitude on behaviour intention was weakened.

Conflicts in construction workers' beliefs and feelings generate attitudinal ambivalence, and it may eventually temper their decisions to act safely. To control the ambivalence, managerial strategies should be implemented including decrease of ambivalence in the cognitive attitude, the affective attitude, and the interaction between them. Specifically, safety managers should be consistent to the "safety first" principle, instead of compromising safety under schedule or cost pressures, and avoid the ambivalence caused by conflicts of cognitive attitude. While they continually organize safety trainings, they should also pay special attention to workers' negative feelings and avoid the ambivalence caused by the conflicts of cognitive and affective attitudes. It is also important for the managers to eliminate habitual unsafe behaviour and resistance on safety rules and regulations and develop a positive habit of following safety rules. If managers encourage a caring environment to make workers believe their coworkers will expect them to follow safety rules, the safety performance may improve. However, managers may take advantage of attitudinal ambivalence when they try to eliminate habitual unsafe behaviour by introducing intensive safety training and intervention to arouse the ambivalence first and then changing construction workers' unsafe attitude by controlling the ambivalence.

Besides attitudinal ambivalence, construction workers' groups had an impact on attitudinal ambivalence and behaviour intentions through the factor of social norms because social influence is one of the factors in personal decisions. It has been traditionally observed that the pressure from workmates of certain social norms influenced workers' behaviour [49]. In construction safety research, Yagil and Luria suggested high-quality friendship compensated for inequity of safety climate and improved workers' safety attitude and behaviour [35]. This research revealed the influence of social norm to intentions. Future research may be focused on exploring the mechanism of the influence of social norms, and the organizational strategies to improve safety attitude in construction groups of migrant workers with high mobility.

One of the limitations of the proposed TPB model was that it did not include the behaviour component. By collecting real data of construction workers' unsafe behaviour with information technology, it is possible to verify whether the proposed TPB model could predict unsafe behaviour effectively. Findings of this research explained the conflicts in construction workers' safety decisionmaking process with the partial mediating factor of attitudinal ambivalence and enriched the research on safety management with psychological theories and methods. Future work is also concentrated on the factors leading to attitudinal ambivalence and their interactive dynamics to influence the attitudinal ambivalence and eventually the safety behaviour.

\section{Conclusions}

This research discussed the attitudinal ambivalence that influenced the intentions of behaviour and identified the impact path of attitudinal ambivalence on behavioural intention and safety behaviour. The results obtained from the questionnaire survey on 228 construction workers showed that safety recognition, social norms, and perceived behavioural control had significant influence on intentions of unsafe acts. The results from structure equation modelling (SEM) analysis explained $82.0 \%$ of its variance. Model fitting showed that attitudinal ambivalence had a partial mediating impact on unsafe behavioural intentions, while attitudinal ambivalence and subjective norms were the strongest predictors of intention. 


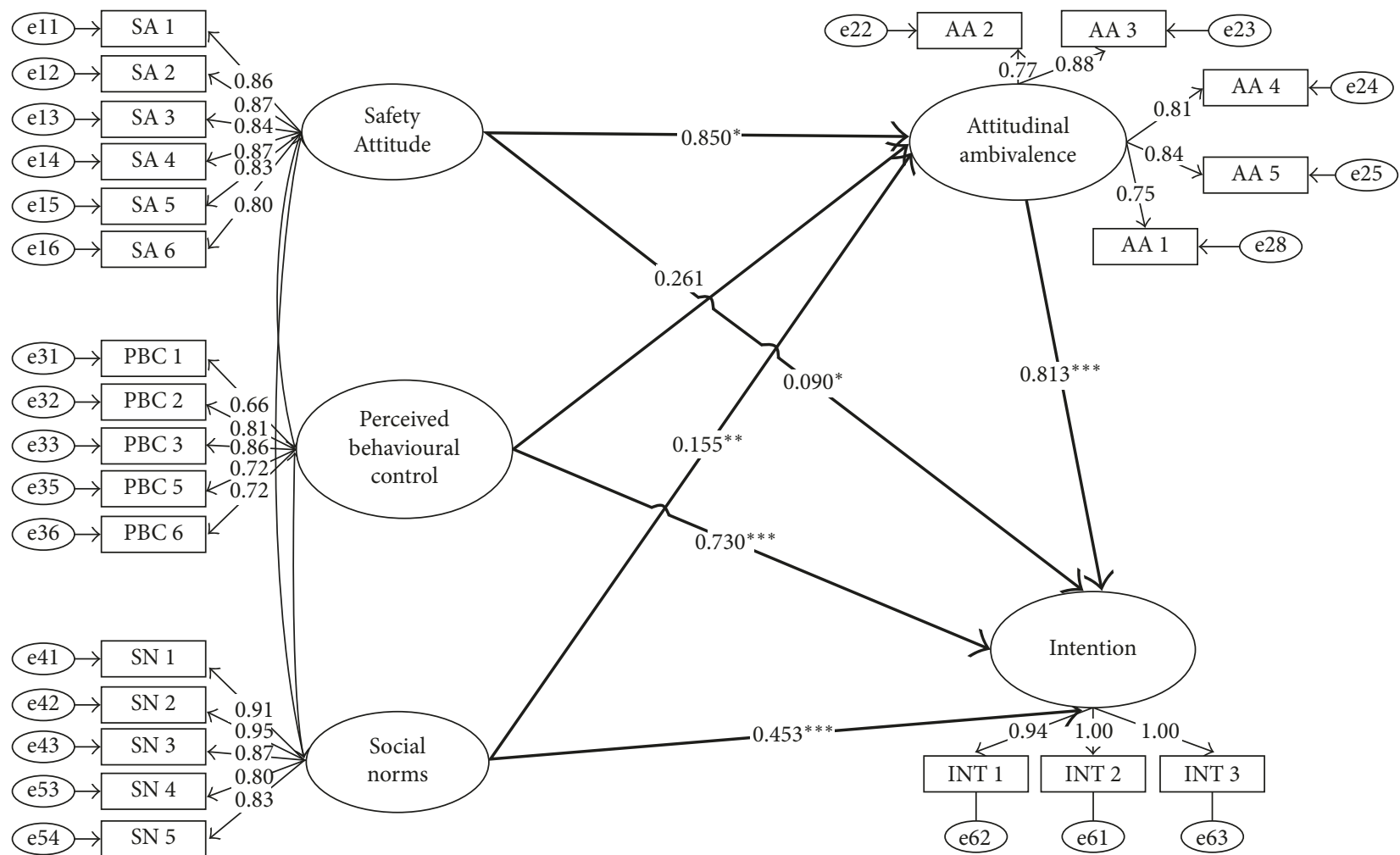

Figure 2: Fitting of the partial mediating model (2-column fitting image). Note. ${ }^{* * *}$ Significance level is $p<0.001$, ${ }^{* *}$ significance level is $p<0.01$, and * significance level is $p<0.05$.

This study applied psychological theories to develop an understanding of the leading factors leading to safety behaviour in construction. Anchoring at the psychological perspective is an innovative and developing point of view in construction safety research. In expanding this line of research to other safety violations, researchers and practitioners may design more effective and humanoriented safety interventions. Subjective norms also had a substantial influence on intentions; encouraging safety communications and fostering positive safety climate could promote the favourable subjective norms. The introduction of attitudinal ambivalence in this research showed its ability to account for the prediction of intention and behaviour and will be the first step in understanding the occurrence, the expansion, and the impact of ambivalent attitude in construction worker groups.

The main contribution of this research is the use of psychological approach to provide a clear picture of why and how unsafe behaviour happens. As a partial mediating factor, attitudinal ambivalence provided an explanation of the complex and evolving decision-making process behind unsafe behaviour under multiple information sources and conflicting environments.

\section{Appendix}

\section{Questionnaire of Workers' Safety Attitude and Behaviour (Note: This Is a Translation of the Original Questionnaire in Chinese)}

Dear colleagues,

Thank you very much for taking your time in this survey.

This is a research survey on workers' safety attitude and behaviour. It will help us get to know your safety views, attitude and behaviour better, and eventually it will help the construction industry and yourself. We sincerely hope you could treat it carefully and tell us your real thoughts. We assure you that you are not required to put your name anywhere in the survey, and your answers will be treated in full confidential and used only for research.

Your answers are valuable. Thank you again for your cooperation!

Part 1: Personal Information

Please tick " $\sqrt{ }$ " when it fits your situation.

(1) Your age: 口 under 20 口 20 29 口 30 39 口 40 49 口 over 50 
Table 5: Safety attitude scale.

Safety attitude (not shown on paper)

1. There are various and complex risks in construction,

SA1 are you familiar about the risks that can be harmful to your health during work:

2. Even experts did not agree

SA2 on whether construction risks could be avoided. I think risks:

3. My coworkers and I

SA3 generally believe that correctly wearing PPE ( ) avoid accidents

SA4 4. I believe to correctly wear PPE is
Not very familiar
Somehow familiar but not very much
Familiar

Very familiar

Cannot be avoided at Almost cannot Some can be avoided Basically can Definitely can all be avoided and some cannot be avoided be avoided

\begin{tabular}{|c|c|c|c|c|c|c|}
\hline SA4 & PPE is & Not necessary & Impossible & Not sure & A should-do & A must-do \\
\hline SA5 & $\begin{array}{l}\text { 5. The safety rules are } \\
\text { complicated, are you familiar } \\
\text { with all PPE supposed to wear } \\
\text { in the work: }\end{array}$ & Very unfamiliar & $\begin{array}{l}\text { Not very } \\
\text { familiar }\end{array}$ & $\begin{array}{l}\text { Somehow familiar but } \\
\text { not very much }\end{array}$ & Familiar & Very familiar \\
\hline SA6 & $\begin{array}{l}\text { 6. It could be complicated, are } \\
\text { you familiar with all the } \\
\text { situations to wear PPE? }\end{array}$ & Very unfamiliar & $\begin{array}{l}\text { Not very } \\
\text { familiar }\end{array}$ & $\begin{array}{c}\text { Somehow familiar but } \\
\text { not very much }\end{array}$ & Familiar & Very familiar \\
\hline SA7 & $\begin{array}{l}\text { 7. My coworkers and I are ( ) to } \\
\text { take trainings on how to wear } \\
\text { PPE correctly }\end{array}$ & Happily willing & Willing & Not sure & Reluctant & Not willing \\
\hline
\end{tabular}
PPE correctly

It would not be

SA8

\section{Wearing PPE correctly, I feel It would be better if I a problem} ()

do not have to if I do not wear

Sometimes, safe

it

Attitudinal ambivalence (not shown on paper)

\begin{tabular}{|c|c|c|c|c|c|c|}
\hline \multicolumn{7}{|c|}{ Attitudinal ambivalence (not shown on paper) } \\
\hline AA1 & 9. Wearing PPE could be: & Very comfortable & Comfortable & Not sure & Uncomfortable & $\begin{array}{c}\text { Very } \\
\text { uncomfortable }\end{array}$ \\
\hline AA2 & $\begin{array}{l}\text { 10. Many people are not used } \\
\text { to wearing PPE, and I: }\end{array}$ & Am used to it & $\begin{array}{l}\text { Am getting } \\
\text { used to it }\end{array}$ & Am not sure & $\begin{array}{l}\text { Am not very } \\
\text { used to it }\end{array}$ & $\begin{array}{l}\text { Am not used to } \\
\text { it } \\
\end{array}$ \\
\hline AA3 & $\begin{array}{l}\text { 11. I ( ) the experience of not } \\
\text { wearing PPE and accidents } \\
\text { happened }\end{array}$ & $\begin{array}{l}\text { Have not } \\
\text { encountered or heard }\end{array}$ & $\begin{array}{c}\text { Have not } \\
\text { encountered }\end{array}$ & Not sure & Have heard & $\begin{array}{c}\text { Have } \\
\text { encountered }\end{array}$ \\
\hline AA4 & $\begin{array}{l}\text { 12. It takes ( ) to finish the work } \\
\text { if I keep PPE on: }\end{array}$ & Much longer & A little longer & Not sure & A little faster & Much faster \\
\hline AA5 & $\begin{array}{l}\text { 13. I can perform better if I } \\
\text { wear PPE }\end{array}$ & Sure & I think so & Not sure & Probably not & No \\
\hline AA6 & $\begin{array}{l}\text { 14. My coworkers and I feel ( ) } \\
\text { working in this site }\end{array}$ & Very dangerous & Not very safe & Not sure & Safe & Very safe \\
\hline AA7 & $\begin{array}{l}\text { 15. My coworkers and I ( ) in } \\
\text { learning how to wear PPE }\end{array}$ & $\begin{array}{c}\text { Do not think it } \\
\text { necessary }\end{array}$ & $\begin{array}{l}\text { Are not very } \\
\text { interested }\end{array}$ & Not sure & Are interested & $\begin{array}{c}\text { Are very } \\
\text { interested }\end{array}$ \\
\hline AA8 & $\begin{array}{l}\text { 16. I ( ) the experience of not } \\
\text { wearing PPE and accidents } \\
\text { happened }\end{array}$ & $\begin{array}{l}\text { Have not } \\
\text { encountered or heard }\end{array}$ & $\begin{array}{c}\text { Have not } \\
\text { encountered }\end{array}$ & Not sure & Have heard & $\begin{array}{c}\text { Have } \\
\text { encountered }\end{array}$ \\
\hline \multicolumn{7}{|c|}{ Subjective norm (not shown on paper) } \\
\hline SN1 & $\begin{array}{l}\text { 17. I think good relationships } \\
\text { with my coworkers ( ) help me } \\
\text { wear PPE correctly }\end{array}$ & Is impossible to & $\begin{array}{l}\text { Is likely } \\
\text { impossible to }\end{array}$ & Not sure & Possibly will & Will \\
\hline SN2 & $\begin{array}{l}\text { 18. I think good relationships } \\
\text { with my supervisors ( ) help me } \\
\text { wear PPE correctly }\end{array}$ & Is impossible to & $\begin{array}{l}\text { Is likely } \\
\text { impossible to }\end{array}$ & Not sure & Possibly will & Will \\
\hline
\end{tabular}
Most of the
time safe

Can effectively

Sometimes can and sometimes cannot 
TABLE 5: Continued.

\begin{tabular}{|c|c|c|c|c|c|c|}
\hline SN3 & $\begin{array}{l}\text { 19. If I failed to wear PPE } \\
\text { correctly, my coworkers ( ) } \\
\text { remind me }\end{array}$ & Would & Some would & Sometimes would & $\begin{array}{l}\text { Basically } \\
\text { would not }\end{array}$ & Would not \\
\hline SN4 & $\begin{array}{l}\text { 20. I think my family ( ) hope } \\
\text { me to wear PPE correctly }\end{array}$ & Do not care to & Might & Somewhat & Generally & Greatly \\
\hline SN5 & $\begin{array}{l}\text { 21. Do you have the experience } \\
\text { that you had a tense } \\
\text { relationship with the foremen } \\
\text { and not able to wear PPE } \\
\text { correctly? }\end{array}$ & No & Barely not & Not sure & Possibly yes & Definitely yes \\
\hline \multicolumn{7}{|c|}{$\begin{array}{l}\text { Perceived behavioural control } \\
\text { (not shown on paper) }\end{array}$} \\
\hline PBC1 & $\begin{array}{l}\text { 22. I am ( ) to wear PPE } \\
\text { correctly }\end{array}$ & Not confident & $\begin{array}{l}\text { Not very } \\
\text { confident }\end{array}$ & Not sure if I will & Confident & Very confident \\
\hline $\mathrm{PBC} 2$ & $\begin{array}{l}\text { 23. My coworkers and I believe } \\
\text { that without mandatory rules, } \\
\text { we ( ) wear the PPE correctly }\end{array}$ & Will still & May & Not sure if we will & May not & Will not \\
\hline $\mathrm{PBC} 3$ & $\begin{array}{l}\text { 24. I ( ) felt that it does not } \\
\text { matter if I do not follow safety } \\
\text { guidelines for a few times } \\
\text { during work }\end{array}$ & Never & Barely & Not sure & Possibly & Have \\
\hline PBC4 & $\begin{array}{l}\text { 25. I ( ) wear PPE when I am } \\
\text { exhausted }\end{array}$ & Will not & $\begin{array}{l}\text { Will possibly } \\
\text { not }\end{array}$ & Am not sure if I will & Will possibly & Will definitely \\
\hline PBC5 & $\begin{array}{l}\text { 26. I am ( ) given the } \\
\text { information I need to follow } \\
\text { safety guidelines }\end{array}$ & Fully & Mostly & Partly & Barely & Not \\
\hline PBC6 & $\begin{array}{l}\text { 27. If no one reminds me, I ( ) } \\
\text { wear PPE }\end{array}$ & Will not & Mostly will not & Sometimes will & $\begin{array}{l}\text { Basically } \\
\text { happy to }\end{array}$ & Am happy to \\
\hline PBC7 & $\begin{array}{l}\text { 28. I have to keep wearing PPE } \\
\text { correctly: }\end{array}$ & Definitely & Mostly & Not sure & Impossible & Not necessarily \\
\hline \multicolumn{7}{|c|}{ Intention (not shown on paper) } \\
\hline INT1 & $\begin{array}{l}\text { 29. I ( ) to wear PPE correctly } \\
\text { in the next four weeks }\end{array}$ & Will not & May not & Not sure & May & Will \\
\hline INT2 & $\begin{array}{l}\text { 30. In the last two months, I } \\
\text { feel like everyone has ( ) worn } \\
\text { PPE correctly }\end{array}$ & Not & Not always & Not sure & Occasionally & Always \\
\hline INT3 & $\begin{array}{l}\text { 31. In the last six months, I feel } \\
\text { like everyone has ( ) worn PPE } \\
\text { correctly }\end{array}$ & Not & Not always & Not sure & Occasionally & Always \\
\hline
\end{tabular}

(2) Your education: 口 Primary school 口 Middle school 口 High school 口 Occupational education 口 University or higher

(3) You have been working in construction industry for: 口 $0 \sim 3$ years 口 4 7 years 口 8 10 years 口 More than 10 years

(4) You have been working on this site for: 口Less than 6 months 口 6 to 12 months 口 1 year or more

(5) Your trade: $\square$ Bar benders $\square$ Concrete workers 口 Frame workers 口 Electronics 口 Labourers 口 Carpenters 口Drivers 口 Others

Part 2: Safety Attitude Scale (Table 5).

\section{Data Availability}

The data used to support the findings of this study are available from the corresponding author upon request.

\section{Conflicts of Interest}

The authors declare no conflicts of interest.

\section{Acknowledgments}

This work was supported financially by the National Natural Science Foundation of China (51708039), the Shaanxi Province Science Foundation for Youths (2017JQ7005), and the Fundamental Research Funds for the Central Universities of China (310823170432).

\section{References}

[1] J. Wang, P. X. W. Zou, and P. P. Li, "Critical factors and paths influencing construction workers' safety risk tolerances," Accident Analysis and Prevention, vol. 93, pp. 267-279, 2016. 
[2] R. M. Choudhry and D. Fang, "Why operatives engage in unsafe work behavior: investigating factors on construction sites," Safety Science, vol. 46, no. 4, pp. 566-584, 2008.

[3] P. X. W. Zou and R. Sunindijo, Strategic Safety Management in Construction and Engineering, Wiley-Blackwell, Oxford, UK, 2015.

[4] X. Wu, W. Yin, C. Wu, and X. Luo, "The spillover effects on employees' life of construction enterprises' safety climate," Sustainability, vol. 9, no. 11, p. 2060, 2017.

[5] K. Misiurek and B. Misiurek, "Methodology of improving occupational safety in the construction industry on the basis of the TWI program," Safety Science, vol. 92, pp. 225-231, 2017.

[6] Q. Zhou, D. Fang, and S. Mohamed, "Safety climate improvement: case study in a Chinese construction company," Journal of Construction Engineering and Management, vol. 137, no. 1, pp. 86-95, 2011.

[7] R. Gao, A. Chan, W. Utama, and H. Zahoor, "Multilevel safety climate and safety performance in the construction industry: development and validation of a top-down mechanism," International Journal of Environmental Research and Public Health, vol. 13, no. 11, p. 1100, 2016.

[8] D. Fang, C. Zhao, and M. Zhang, "A cognitive model of construction workers' unsafe behaviors," Journal of Construction Engineering and Management, vol. 142, no. 9, article 04016039, 2016.

[9] I. Ajzen, "The theory of planned behavior," Organizational Behavior and Human Decision Processes, vol. 50, no. 2, pp. 179-211, 1991.

[10] G. J. Fogarty and A. Shaw, "Safety climate and the theory of planned behavior: towards the prediction of unsafe behavior," Accident Analysis and Prevention, vol. 42, no. 5, pp. 14551459, 2010.

[11] C. S. Fugas, S. A. Silva, and J. L. Meliá, “Another look at safety climate and safety behavior: deepening the cognitive and social mediator mechanisms," Accident Analysis and Prevention, vol. 45, pp. 468-477, 2012.

[12] Y. Shen, T. Y. Koh, S. Rowlinson, and A. J. Bridge, "Empirical investigation of factors contributing to the psychological safety climate on construction sites," Journal of Construction Engineering and Management, vol. 141, no. 11, article 04015038, 2015.

[13] L. Montoro, S. Useche, F. Alonso, and B. Cendales, "Work environment, stress, and driving anger: a structural equation model for predicting traffic sanctions of public transport drivers," International Journal of Environmental Research and Public Health, vol. 15, no. 3, p. 497, 2018.

[14] K. Jonas, P. Broemer, and M. Diehl, "Attitudinal ambivalence," European Review of Social Psychology, vol. 11, no. 1, pp. 35-74, 2011.

[15] N. Cavazza and A. Serpe, "Effects of safety climate on safety norm violations: exploring the mediating role of attitudinal ambivalence toward personal protective equipment," Journal of Safety Research, vol. 40, no. 4, pp. 277-283, 2009.

[16] L. S. Robson, C. M. Stephenson, P. A. Schulte et al., "A systematic review of the effectiveness of occupational health and safety training," Scandinavian Journal of Work, Environment and Health, vol. 38, no. 3, pp. 193-208, 2012.

[17] I. Ajzen, "From intentions to actions: a theory of planned behavior," in Springer Series in Social Psychology, J. K. J. Beckmann, Ed., Springer, Berlin, Germany, 1985.

[18] D. Jovanović, M. Šraml, B. Matović, and S. Mićić, "An examination of the construct and predictive validity of the selfreported speeding behavior model," Accident Analysis and Prevention, vol. 99, pp. 66-76, 2017.
[19] E. Flowers, P. Freeman, and V. Gladwell, "The development of three questionnaires to assess beliefs about green exercise," International Journal of Environmental Research and Public Health, vol. 14, no. 10, p. 1172, 2017.

[20] Y. M. Goh and N. F. Binte Sa'adon, "Cognitive factors influencing safety behavior at height: a multimethod exploratory study," Journal of Construction Engineering and Management, vol. 141, no. 6, article 04015003, 2015.

[21] K. I. Dunn, P. Mohr, C. J. Wilson, and G. A. Wittert, "Determinants of fast-food consumption. An application of the theory of planned behaviour," Appetite, vol. 57, no. 2, pp. 349-357, 2011.

[22] M. Conner and C. J. Armitage, "Extending the theory of planned behavior: a review and avenues for further research," Journal of Applied Social Psychology, vol. 28, no. 15, pp. 1429-1464, 1998.

[23] I. S. Moan and J. Rise, "Predicting smoking reduction among adolescents using an extended version of the theory of planned behaviour," Psychology and Health, vol. 21, no. 6, pp. 717-738, 2006.

[24] R. M. Choudhry, D. Fang, and H. Lingard, "Measuring safety climate of a construction company," Journal of Construction Engineering and Management, vol. 135, no. 9, pp. 890-899, 2009.

[25] S. Clarke, "The relationship between safety climate and safety performance: a meta-analytic review," Journal of Occupational Health Psychology, vol. 11, no. 4, pp. 315-327, 2006.

[26] T. A. Arcury, T. Mills, A. J. Marín et al., "Work safety climate and safety practices among immigrant Latino residential construction workers," American Journal of Industrial Medicine, vol. 55, no. 8, pp. 736-745, 2012.

[27] S. Mohamed, T. H. Ali, and W. Y. V. Tam, "National culture and safe work behaviour of construction workers in Pakistan," Safety Science, vol. 47, no. 1, pp. 29-35, 2009.

[28] B. H. W. Guo, T. W. Yiu, and V. A. González, "Predicting safety behavior in the construction industry: development and test of an integrative model," Safety Science, vol. 84, pp. 1-11, 2016.

[29] X. Wu, W. Yin, C. Wu, and Y. Li, "Development and validation of a safety attitude scale for coal miners in china," Sustainability, vol. 9, no. 12, p. 2165, 2017.

[30] J. Bohm and D. Harris, "Risk perception and risk-taking behavior of construction site dumper drivers," International Journal of Occupational Safety and Ergonomics, vol. 16, no. 1, pp. 55-67, 2015.

[31] P. J. Leather, "Attitudes towards safety performance on construction work: an investigation of public and private sector differences," Work and Stress, vol. 2, no. 2, pp. 155-167, 1988.

[32] D. Zohar and O. Tenne-Gazit, "Transformational leadership and group interaction as climate antecedents: a social network analysis," Journal of Applied Psychology, vol. 93, no. 4, pp. 744-757, 2008.

[33] Q. Li, C. Ji, J. Yuan, and R. Han, "Developing dimensions and key indicators for the safety climate within china's construction teams: a questionnaire survey on construction sites in Nanjing," Safety Science, vol. 93, pp. 266-276, 2017.

[34] R. Alsamadani, M. Hallowell, and A. N. Javernick-Will, "Measuring and modelling safety communication in small work crews in the US using social network analysis," Construction Management and Economics, vol. 31, no. 6, pp. 568-579, 2013. 
[35] D. Yagil and G. Luria, "Friends in need: the protective effect of social relationships under low-safety climate," Group and Organization Management, vol. 35, pp. 727-750, 2010.

[36] H. Lingard, T. Cooke, and N. Blismas, "Coworkers' response to occupational health and safety," Engineering, Construction and Architectural Management, vol. 18, no. 2, pp. 159-175, 2011.

[37] S. Lyu, C. Hon, A. Chan, F. Wong, and A. Javed, "Relationships among safety climate, safety behavior, and safety outcomes for ethnic minority construction workers," International Journal of Environmental Research and Public Health, vol. 15, no. 3, p. 484, 2018.

[38] M. Conner, P. Sparks, R. Povey, R. James, R. Shepherd, and C. J. Armitage, "Moderator effects of attitudinal ambivalence on attitude-behaviour relationships," European Journal of Social Psychology, vol. 32, no. 5, pp. 705-718, 2002.

[39] J. R. Priester and R. E. Petty, "The gradual threshold model of ambivalence: relating the positive and negative bases of attitudes to subjective ambivalence," Journal of Personality and Social Psychology, vol. 71, no. 3, pp. 431-449, 1996.

[40] D. W. Bell, V. M. Esses, and G. R. Maio, "The utility of openended measures to assess intergroup ambivalence," Canadian Journal of Behavioural Science, vol. 28, no. 1, pp. 12-18, 1996.

[41] J. R. Smith, M. A. Hogg, R. Martin, and D. J. Terry, "Uncertainty and the influence of group norms in the attitudebehaviour relationship," British Journal of Social Psychology, vol. 46, no. 4, pp. 769-792, 2007.

[42] J. R. Priester, R. E. Petty, and K. Park, "Whence univalent ambivalence? From the anticipation of conflicting reactions," Journal of Consumer Research, vol. 34, no. 1, pp. 11-21, 2007.

[43] K. Jonas, P. Broemer, and M. Diehl, "Experienced ambivalence as a moderator of the consistency between attitudes and behaviors," Zeitschrift für Sozialpsychologie, vol. 31, no. 3, pp. 153-165, 2000.

[44] I. W. H. Fung, C. M. Tam, K. C. F. Tung, and A. S. K. Man, "Safety cultural divergences among management, supervisory and worker groups in Hong Kong construction industry," International Journal of Project Management, vol. 23, no. 7, pp. 504-512, 2005.

[45] C. Li and N. Li, "The relation among coalminer's self-efficacy, safety attitude and risk-taking behavior," Procedia Engineering, vol. 7, pp. 352-355, 2010.

[46] R. A. Braham, "Community football players' attitudes towards protective equipment-a pre-season measure," British Journal of Sports Medicine, vol. 38, no. 4, pp. 426-430, 2004.

[47] R. Zhou and W. J. Horrey, "Predicting adolescent pedestrians' behavioral intentions to follow the masses in risky crossing situations," Transportation Research Part F: Traffic Psychology and Behaviour, vol. 13, no. 3, pp. 153-163, 2010.

[48] B. S. Everitt, The Cambridge Dictionary of Statistics, Cambridge University Press, Cambridge, UK, 2nd edition, 2002.

[49] N. E. Friedkin and E. C. Johnsen, Social Influence Network Theory: A Sociological Examination of Small Group Dynamics, Cambridge University Press, Cambridge, UK, 2011. 


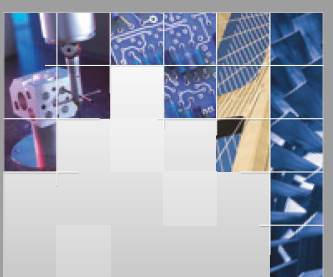

\section{Enfincering}
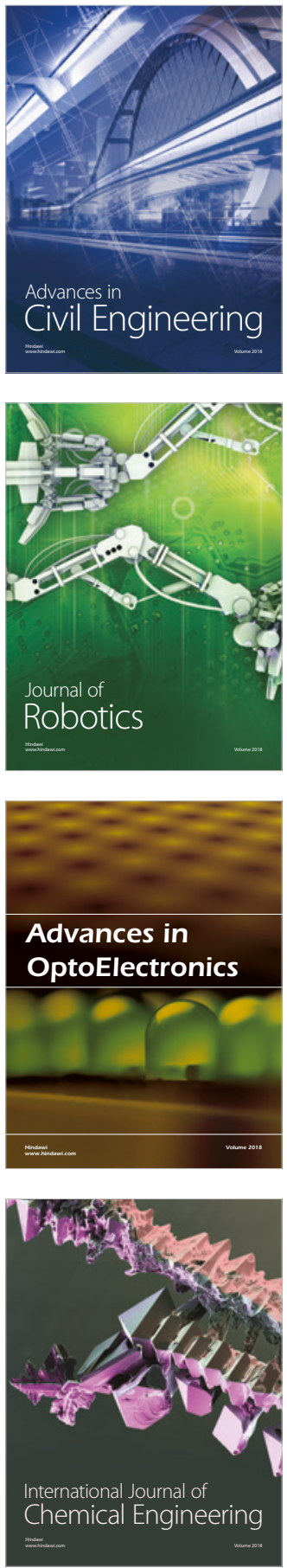

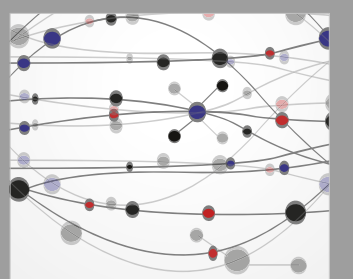

\section{Rotating \\ Machinery}

The Scientific World Journal

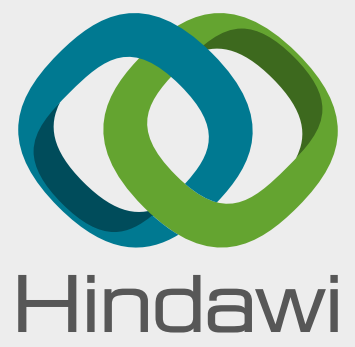

Submit your manuscripts at

www.hindawi.com
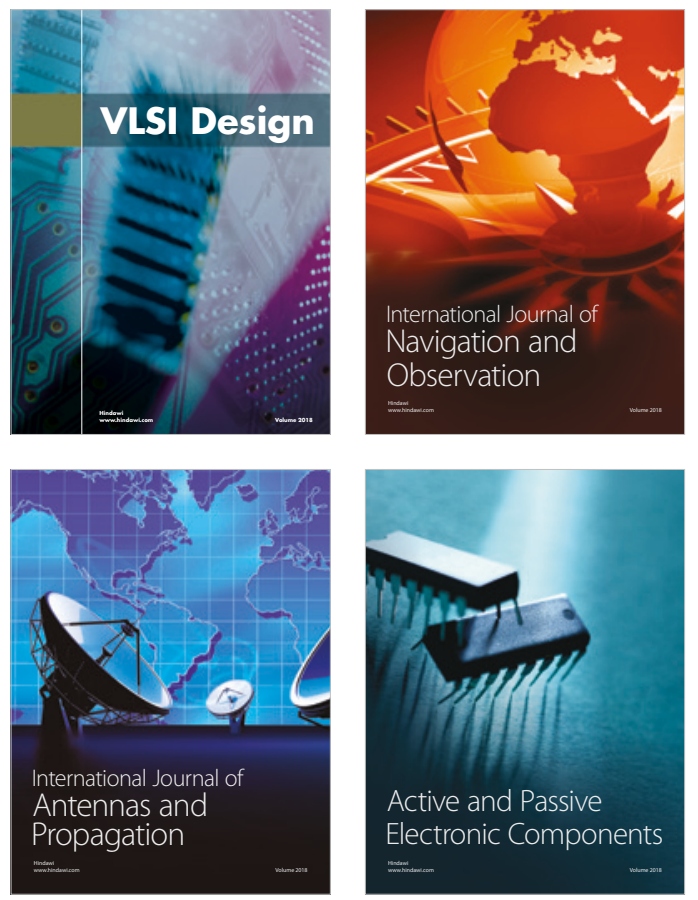
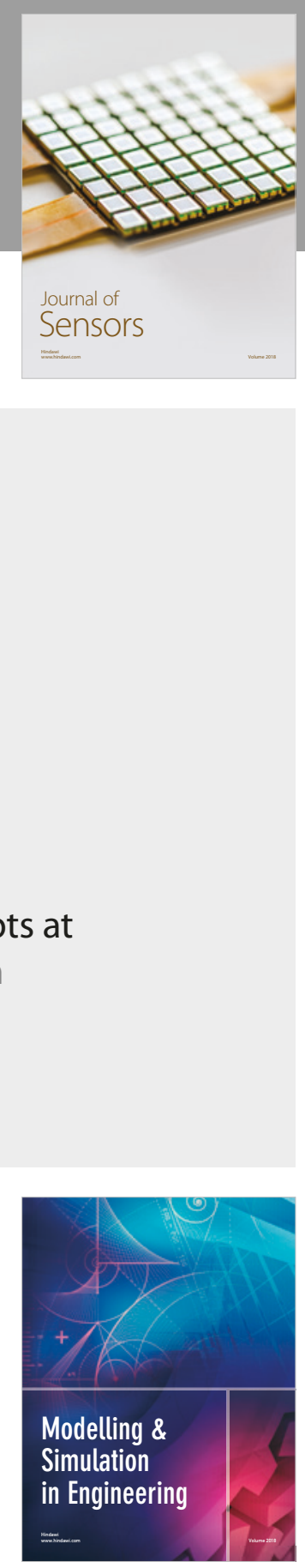

\section{Advances \\ Multimedia}
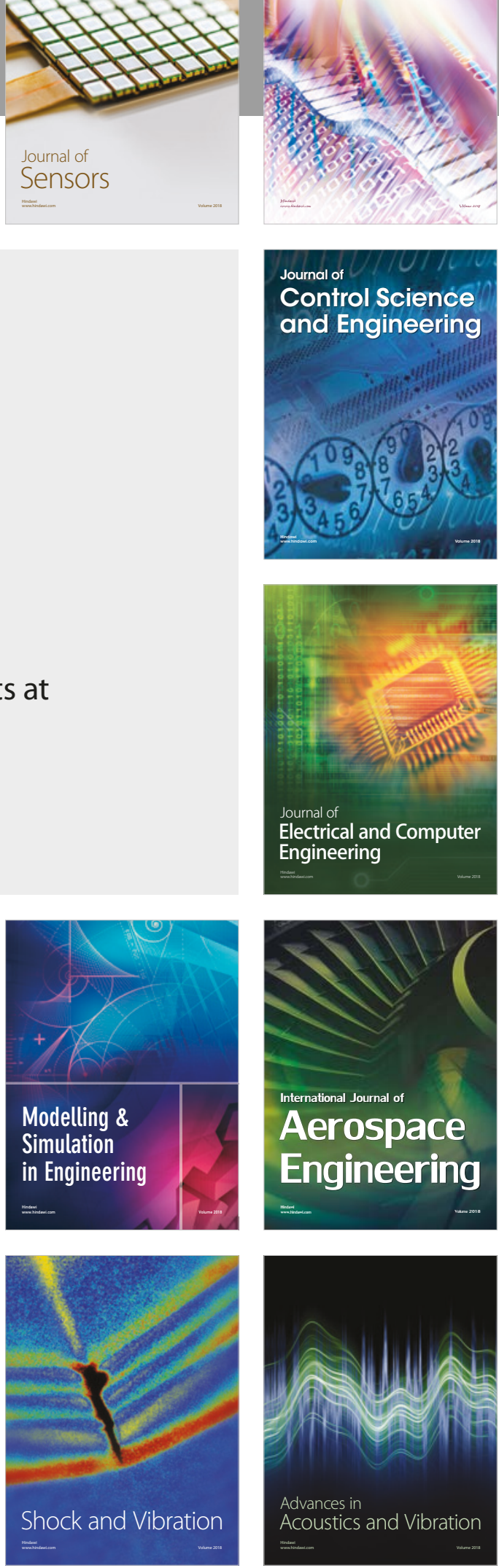